\title{
PROBLEMAS DE METACRÍTICA: OS DISCURSOS SOBRE TEATRO NA ERA DIGITAL
}

\author{
Liliana Beatriz López ${ }^{l}$
}

\begin{abstract}
Resumo
O texto apresenta uma reflexão sobre a crítica teatral argentina, considerando a abordagem de espetáculos contemporâneos que podem ser classificados como de um "teatro performativo". A autora define metacrítica como a análise de um metadiscurso -a crítica teatral-, e observa que ainda que a crítica seja um sistema autônomo, este apresenta mudanças de paradigmas que são internas ao discurso. A crítica e os novos meios como blogs (internet).
\end{abstract}

Palavras chave: crítica, teatro performativo, internet.

\begin{abstract}
The text reflect $\mathrm{s}$ about the theatrical critic in Argentina, considering contemporary productions that can be classified as "performative theater". The author defines "meta critic" as an analysis of a "meta discourse", and observes that even though the critic is an autonomous system, it presents changes of paradigms, that are inside the discourse. The critic and the new media, as blogs in the Internet.
\end{abstract}

Key words: critic, performative theatre, internet.

Como umbral introdutório, considero apropriado explicitar a premissa a partir da qual está organizado este artigo: a crise dos paradigmas teóricos e das práticas discursivas cujo objeto é o teatro, se intensificou de maneira vertiginosa.

Ao mesmo tempo, esta proliferação discursiva constitui um sinal sobre a que evitaremos momentaneamente um julgamento valorativo - que nos demanda uma reflexão, que não pode assumir outro estatuto que não seja metacrítico, com todos os riscos que implica o fato de participar, de estar imerso, de um ou outro modo, na prática e a recepção dos discursos.

Definimos metacrítica como a análise de um metadiscurso -a crítica teatral- um discurso sobre a prática teatral. Faço um recorte sobre teatro

1Professora do Instituto Universitario Nacional de las Artes e da Universidad de Buenos Aires 


\section{Urdimento}

${ }^{2} \mathrm{Na}$ segunda mudança, verificado na imprensa escrita de Buenos Aires ao redor dos anos sessenta, consiste em um fenômeno denominado "modernização discursiva". Seus principais expoentes foram as revistas de interesse geral Primera plana e Confirmado. No âmbito das revistas teatrais, na mesma década, Talía e Teatro XX argentino, e apresento a possibilidade de um debate sobre se estes fenômenos - por causa da globalização e das novas tecnologias da comunicação - também ocorrerem no Brasil.

A arte teatral sempre vai a frente dos discursos que a ela se referem, já sejam teóricos, acadêmicos ou jornalísticos; esta localização propõe constantes desafios, já que a crítica deve ajustar seu olhar e produzir novos paradigmas na sua leitura. Esta afirmação pode ser verificada mediante a história do teatro: cada nova forma, rupturista ou inovadora, demandou um tempo para ser assimilada, logo do rechaço inicial, na maior parte dos casos.

Mas, se consideramos a crítica como um sistema autônomo, ou não totalmente dependente de seu objeto, podemos observar que produziram-se mudanças de paradigmas, que são internos ao discurso. Entre essas mudanças, assinalarei ao menos uma, que está referida em relação ao objeto ${ }^{2}$. Este não tem um estatuto dado de antemão, nem é exterior ao que pesquisa, nem "é" do mesmo modo, de uma vez e para sempre, se não que constituiu uma construção instável, provisória e aberta às mudanças, que muitas vezes, os próprios fenômenos provocam. Vale recordar o que assinalava, faz já muito tempo, Juri Tinianov a respeito da história literária: cada novo evento, cada acontecimento comove toda a história precedente, modifica as séries anteriores.

Abordarei duas problemáticas que repercutem sobre diferentes superfícies de inscrição dos discursos sobre teatro, o primeiro pertenece à esfera acadêmica, que abarca tanto a pesquisa como a produção de teorias e metodologias.

Mas, ao afirmar "discursos sobre teatro", surge o problema da delimitação do objeto, que resulta complexo, aberto e dinâmico, e, consequentemente, potencialmente abordável desde várias disciplinas ao mesmo tempo.

Muito recentemente, Patrice Pavis reformulava -a respeito de seus trabalhos anteriores- o papel e o objeto da crítica nesta época:

Sem dúvida: uma mudança de paradigma da prática da encenação fez inoperantes as matrizes da análise, ao menos temporalmente. A concepção estrutural, funcionalista, semiológica da encenação, que concebia a representação como um texto espetacular e um sistema semiológico, não funciona mais. Esta mudança não é um fato totalmente novo, ainda que a crítica francesa não o tenha registrado ainda. O teatro parece descobrir que o essencial não reside no resultado, na representação terminada, mas sim no processo produzido. A encenação deviu performance, no sentido inglês do termo: ela 


\section{Urdimento}

participa em uma ação, está no devenir permanente. É preciso enfocar o espetáculo em seus dois extremos: suas origens e suas prolongações, compreender de onde vem a ação performativa e para onde vai. ${ }^{3}$

Esta posição de Pavis, me coloca vários interrogantes. Uma vez aceita, a encenação, como objeto de estudo, se faria evanescente, desapareceria, e a análise crítica deveria se ocupar unicamente do eixe "produção-recepção" sumamente complexo-. Pavis oscila, neste parágrafo, em atribuir esta situação do teatro contemporâneo, por um lado, às características do próprio teatro; por outro, a uma diferente função do discurso crítico.

Poderia colocar nesta mesma linha postulada por Pavis, a Hans-Thies Lehman, que no seu livro O teatro pós-dramático, assinala uma dobra desde os anos setenta, no contexto da comunicação massiva multimedial, que afirma a existência de formas teatrais que já não se produzem como translação ilustrativa de um drama prévio.

Resulta evidente, para além das colocações de Pavis, que o objeto da pesquisa e da crítica teatral é o resultado de uma forte mudança de paradigma de não faz muito tempo: se produziu quase ao mesmo tempo em que se constituía a própria atividade da pesquisa como um espaço autônomo dos estudos literários. Denomino esta mudança de "giro cenocêntrico", para significar que se produziu uma virada discursiva desde o texto dramático em direção à encenação, no sentido de que esta já não é concebida como a "representação" ou "tradução" de um texto.

Portanto, além do campo fenomênico, o objeto que constrói a pesquisa ou o olhar do pesquisador, a partir de tal giro, ultrapassa as metodologias com as quais vinha-se estudando - salvo exceções - o teatro até então, e na medida em que isto sucede, o pesquisador, às vezes de uma maneira intuitiva, às vezes com mais consciência disso, recorre ao auxílio de outras disciplinas, entre elas, a antropologia, a psicoanálise, a ciência política, a sociologia. Também se está levando a cabo o processo inverso: é desde estas disciplinas que se aborda o teatro, completando os alvos dos discursos específicos. Logicamente, estes não deixaram de existir, já que as universidades, faculdades ou departamentos têm áreas determinadas, com disciplinas que abordam o teatro desde a teoria, a análise, a história, a prática. Neste sentido, o primeiro problema que desejo abordar, tem de ver com a distinção entre multidisciplinariedade e interdisciplinariedade, segundo a distinção feita pelo antropólogo e sociólogo Héctor Vázquez, em La investigación sociocultural, onde redefine o conceito de disciplina ${ }^{4}$ e distingue entre ambos enfoques:
${ }^{3}$ PAVIS, op.cit. (2007,

p. 37). [T.A.]
4"... por disciplina entendemos 0 ensino dos critérios mediante os quais se constroem enfoques teóricos que procuram compreender a natureza e 0 comportamento do real selecionado previamente" (1994, p. 110). 


\section{Urdimento}

${ }^{5}$ NT. O processo de independência argentina se iniciou em 25 de maio de 1810, e se consolidou com a unificação do país com a realização do Congresso de Tucumán em 1816.

${ }^{6}$ Este grupo foi criado por Diqui James e Gaby Kerpel, ambos participantes do grupo De La Guardia, importante companhia teatral de Buenos Aires, que por sua vez representou um desdobramento do grupo Organización La Negra que na metade dos anos 80 revolucionou a cena portenha com espetáculos performático. De acordo com os fundadores da La Negra o projeto inicial do coletivo teve uma forte influência do grupo espanhol Fura Dels Baus.

${ }^{7}$ No melhor dos casos, se fizeram entrevistas aos realizadores. Por exemplo, Ana Seoane entrevistou a Diqui James (jornal Perfil, 29/5/2010). Ou uma resenha muito geral, que enumerava elementos, mas não era exaustiva, como a de Laura Falcoff, na seção Sociedade, em Clarín, 26 mai. 2010.
Por multidisciplinariedade entendemos a justaposição de enfoques teóricos diferentes sobre os mesmos problemas a partir de disciplinas distintas, sem chegar a estabelecer um denominador teórico comum. Não se produz convergência teórica-metodológica.

Pelo contrario, é mais pertinente e operativa a noção segundo a qual

Interdisciplinariedade é uma categoria referida à pesquisa. E, ademais, implica diferentes níveis de integração teóricos-metodológicos entre cada disciplina; mediante a construção de um comum denominador teórico nos dilemas colocados nas zonas fronteriças intermediárias. Tudo isso supõe um esforço de síntese em diferentes graus e níveis (1994, p. 110).

Esta integração também produz tensões, de difícil resolução na dinâmica da pesquisa grupal, especialmente na hora de construir um denominador comum teórico, um espaço de confluência, que exige também um grau de renúncia parcial a respeito da própria disciplina; mas este parece ser o caminho mais viável da pesquisa teatral nos tempos que virão.

Sobre a crítica não acadêmica ou jornalística, sua situação parece ser de retirada e desconcerto ante fenômenos que não se enquadram na categoria mais convencional do acontecimento teatral.

Para comentar este estado de coisas, vou analisar um caso, que precisamente por sua enorme ressonância, fica ainda mais chamativa a omissão da crítica: o "desfile" [em Buenos Aires] por ocasião dos festejos do Bicentenário da Independência Argentina $^{5}$, sob responsabilidade do grupo teatral Fuerza Bruta ${ }^{6}$. Dado que no momento da escritura desse texto transcorreu muito pouco tempo do evento mencionado, é lógico supor que a crítica acadêmica ainda não pode avaliar este fenômeno; mas para os tempos da crítica de meios, o prazo já expirou, e se pode concluir que nem as seções de espetáculos dos periódicos impressos, nem os web-sites de crítica teatral identificaram que se tratava de um acontecimento teatral, além de todas outras possíves considerações. ${ }^{7}$

As mais interessantes leituras divulgadas nos meios provieram de sociólogos e filósofos -Horacio González, Eduardo Grüner, Ricardo Foster-que centraram a reflexão em aspectos políticos e sociológicos. Horacio González, no entanto, em seu relato introduz categorias estéticas e específicamente teatrais: "Uma mostra de arte industrial...", "Arte baseada no esforço muscular e a coreografia aérea...”, “...modelo narrativo que fundiu espaços abertos e urbanos e dramaturgia situacionista...”, “...realismo pedagógico de rua, 


\section{Urdimento}

com faíscas brechtianos e palcos arquitetônicos geométricos...", e "Herdeiro do circo, da televisão e da praça medieval, este teatro posvanguardista vive de criar pequenas miniaturas emotivas com objetos de cena de dimensões portuárias e engenharia de precisão". ${ }^{8}$

O marco teórico-disciplinar predominante é a política, até no caso de um teatrista, o dramaturgo e diretor Rafael Spregelburd, quem leu o evento como uma batalha de símbolos e alegorias, concluindo assim "mas ao dia seguinte, com a rua ainda suja de retro-rave, notei que a primeira triunfadora da batalha simbólica era a classe política. ${ }^{9}$

No suplemento cultural do jornal Clarín, a revista $\tilde{N}$, o espetáculo apresentado por Fuerza Bruta está perdido em uma matéria geral sobre os festejos, sob responsabilidade de um escritor estrangeiro, quem escreve a matéria como uma crônica do passado ${ }^{10}$. Estas duas circunstâncias (ser estrangeiro, o que é remarcado várias vezes no texto) e escrever como se tudo houvesse sucedido faz tempo, parecem buscar um "efeito de distanciamento", que finalmente fracassa: "E senti o estranho nervosismo de descobrir que pode existir uma coisa mais perigosa que o nacionalismo: o nacionalismo por um país que não é o teu”.

Entre estas leituras não especificamente teatrais, quase como uma reportagem de variedades, agregarei uma que apareceu no suplemento Rural do jornal Clarín, assinada por um representante do setor agropecuário, que se queixa amargamente pela suposta omissão do setor campo no desfile: ${ }^{11}$

Sem nenhuna alusão ao talento dos artistas, o festejo do Bicentenário deixou uma mensagem que tem que ver com a fuerza bruta, e a atividade agropecuária de hoje não se teve em conta, nem pelo que fez, nem pelo que faz, nem pelo que pode fazer. Em uma peça de teatro se pode sugerir qualquer histária; em uma celebração de um novo centenário, não.

Cabe esclarecer que o setor agropecuário teve um carro alegrórico que o representava, com uma estética próxima ao realismo costumbrista, digna de uma cena do teatro gauchesco rioplatense do século XIX. Este carro foi o menos representativo da estética e dos procedimentos do grupo Fuerza bruta, que os mostrou com ênfase nas cenas dedicadas às Madres de Plaza de Mayo, à indústria e às crises econômicas. ${ }^{12}$

A modalidade do desfile de rua ou de carros alegóricos - na realidade, caminhões ou enormes dispositivos mecânicos - remete, por um lado, ao tradicional desfile militar das festas pátrias, mas também aos pageant wagons medievais ingleses. $\mathrm{O}$ espaço urbano foi percorrido pelos carros alegóricos,
${ }^{8}$ Em Página 12, 30 mai. 2010.

9'́dem. Nota 5

10"Sob um frágil sol de maio", por Juan Pablo Meneses, na revista N, n. $348,20 / 05 / 2010$.

${ }^{11}$ Em sua curiosa leitura, supõe que 0 público aplaudiu sem entender: "Se evocou um país de fracassos, desencontros e oportunidades perdidas, de paradigmas equivocados e de lutas políticas e vidas truncadas; ante 0 qual a população não se emocionou, se não que festejou, porque era seu ânimo, independente do que se representava". E que o nome da agrupação, "Fuerza bruta" se transladava simbolicamente às cenas: "Além do empenho dos atores, a triste é que o que refletiram da Pátria foi a força bruta, com a que se conseguia elevar à Argentina, com ajuda de uma grua, para agitála como uma bandeira, que de vez em quando as protagonistas que $a$ representavam -atleticamente preparadas- admiravelmente pudessem suportar". "Bicentenario y fuerza bruta", em Clarín, Suplemento Rural, 5/06/2010.

${ }^{12}$ Todas as cenas mencionadas podem ser vistas no Youtube. 


\section{Urdimento}

${ }^{13}$ Diferentemente das revistas digitais, onde aparecem críticas no sentido mais ortodoxo, artigos, ensaios e entrevistas. que repitiram a cena várias vezes, para que pudesse ser observada pela maior parte dos assistentes. Além deste recurso, que tem uma origem teatral, cada cena também era teatral por si mesma, um fato que passou praticamente desapercebido para a crítica dos meios.

A segunda problemática que abordarei diz respeito aos sujeitos da "transferência" ou divulgação do discurso crítico. Visto que diferentes enunciadores se referem a um acontecimento teatral desde seu próprio enquadre disciplinar ou como representantes de um setor social, discutindo ou discrepando a respeito do "conteúdo" e deixando de lado questões estritamente teatrais; isto não seria problemático se, entre todas estas vozes, não houvesse uma porção significativa de enunciadores pertenecentes ao campo teatral.

A análise deste caso pontual pode-se enlaçar com a problemática da competência do sujeito emissor do discurso.

Vou expor um caso, que por ser extremo, facilita a reflexão sobre o problema que proponho. Este tem estreita relação com a expansão da tecnologia digital que está transformando todos os âmbitos da esfera humana; daí, que ao redor de 1990 surgiu a denominação "era digital”, para substituir à "era da comunicação". Tal expansão também produz mudanças na produção, circulação e recepção dos discursos sobre teatro. Em Buenos Aires se multiplicaram as páginas web e os blogs de "crítica teatral”; em uma primeira instância, podia fazer-se dois recortes: os espaços virtuais de promoção, onde pode-se consultar a programação atualizada, e que além disso, com a passagem do tempo, constituem um importante arquivo cênico. Falamos de datos: ficha técnica, sala ou espaço (costumam até incluir um mapa), foto, horários, preço das entradas e uma breve sinopse, muitas vezes escrita pelos próprios realizadores. Estas informações, em alguns casos, está acompanhada de uma ou duas críticas, e também permite incluir os comentários dos leitores. ${ }^{13}$

Por outro lado, os blogs, mais livres no que se refere às regras de escritura, identidade discursiva, cuja legitimidade é aberta, indizível e indescifrável. Aqui, como exemplo, cito o blog “Felisa critica teatro", subtitulado sugestivamente "Nossa dona de casa também se dedica a ver e comentar peças de teatro" - que, em parte se explica porque começou comentando cinema"linkado" desde "Alternativa teatral", como parte da seção "Opinião e debate". Neste blog não há escritura, mas sim breves vídeos, no quais a senhora comenta algum espetáculo. O termo comentário ainda parece excessivo, considerando a distinção com a crítica realizada por Michel Foucault, já que nem ao menos se trata de una explicação, que ratifica os sentidos mais óbvios da encenação, mas sim de uma soma de impressões a partir do relato da fábula.

A crítica emergeu a partir do século XVIII, na forma de opiniões de 
leitores publicadas nos jornais, e em pouco tempo se diversificou ao otorgarlhe a autoridade do discurso a um conhecedor, às vezes um “juiz” que se excedia em suas funções. Esta legitimidade estava baseada no conhecimento, no fluído manejo dos conceitos, no escorregadio conceito do "gosto".

Recuperando a proposta inicial, concluo que a profusão dos discursos será saudável na medida em que mais vozes possam ser ouvidas, sem preceptivas que as limitem, mas podem se transformar em uma dádiva perigosa -como no último exemplo mencionado- quando se esvaziam de conteúdos críticos.

\section{Referências bibliográficas}

FOUCAULT, Michel. Las palabras y las cosas. Barcelona: Planeta Agostini, 1984

JAMESON, Frederic. Documentos de cultura, documentos de barbarie. Madrid: Visor, 1989.

LEHMAN, Hans-Thies. Le Théâtre postdramatique. Paris: L'Arche Éditeur, 2002.

MASSIP, Francesc. El teatro medieval. Voz de la divinidad, cuerpo de histrión. Barcelona: Montesinos, 1992.

PAVIS, Patrice. La mise en scène contemporaine. Origines, tendances, perspectives. Paris: Armand Colin, 2007.

UBERSFELD, Anne. Notas teóricas sobre el metadiscurso de la crítica teatral In: Gestus, n. 5 (diciembre 1993), pp. 62-67.

VÁZQUEZ, Héctor. La investigación sociocultural. Crítica de la razón teórica y de la razón instrumental. Buenos Aires: Biblos, 1994. 